\title{
Interval Management: Development and Implementation of an Airborne Spacing Concept
}

\author{
Bryan E. Barmore ${ }^{1}$, William J. Penhallegon ${ }^{2}$, Lesley A. Weitz ${ }^{3}$, Randall S. Bone ${ }^{4}$, Ian Levitt ${ }^{5}$, Julie A. Flores \\ Kriegsfeld ${ }^{6}$, Doug Arbuckle ${ }^{7}$, William C. Johnson ${ }^{8}$
}

\begin{abstract}
Interval Management is a suite of ADS-B-enabled applications that allows the air traffic controller to instruct a flight crew to achieve and maintain a desired spacing relative to another aircraft. The flight crew, assisted by automation, manages the speed of their aircraft to deliver more precise inter-aircraft spacing than is otherwise possible, which increases traffic throughput at the same or higher levels of safety. Interval Management has evolved from a long history of research and is now seen as a core NextGen capability. With avionics standards recently published, completion of an Investment Analysis Readiness Decision by the FAA, and multiple flight tests planned, Interval Management will soon be part of everyday use in the National Airspace System. Second generation, Advanced Interval Management capabilities are being planned to provide a wider range of operations and improved performance and benefits. This paper briefly reviews the evolution of Interval Management and describes current development and deployment plans. It also reviews concepts under development as the next generation of applications.
\end{abstract}

\section{Introduction}

Improvements in communication, navigation, and surveillance systems in the National Airspace System (NAS) have led to the development of multiple concepts to improve efficiency and enhance safety. This includes the deployment of Automatic Dependent Surveillance-Broadcast (ADS-B), which provides controllers access to more accurate aircraft state information and more frequent update rates than currently available via radar systems. Aircraft equipped with ADS-B transmitters (ADS-B Out) broadcast highly accurate, Global Navigation Satellite System-based position and velocity information. Aircraft that are equipped with ADS-B receivers (ADS-B In) can receive this surveillance information and use it either for traffic awareness or to manage their own trajectories based on the behavior of other aircraft in the surrounding airspace.

Interval Management (IM) is an ADS-B-enabled suite of applications that uses ground and flight-deck capabilities and procedures to support aircraft-centric relative spacing of aircraft. Relative spacing refers to managing the position of one aircraft to a time or distance in relation to the trajectory of another aircraft, as opposed to a static reference point such as a point on the ground or clock time. This results in improved inter-aircraft spacing precision and will allow aircraft to be spaced more consistently (and in some situations closer to the separation standard) than current operations. The spacing goal can be based on a metering schedule, the applicable separation standard, a miles-in-trail restriction, or any other operationally-needed spacing objective. IM delegates the spacing task to the flight deck and enables flight crews to follow speed guidance generated by avionics to achieve and/or maintain the spacing goal

\footnotetext{
${ }^{1}$ Aerospace Engineer, National Aeronautics and Space Administration, Langley Research Center, Hampton, VA 23681, member.

${ }^{2}$ Principal Systems Engineer, The MITRE Corporation, McLean, VA 22102.

${ }^{3}$ Lead Simulation Modeling Engineer, The MITRE Corporation, McLean, VA 22102, Senior AIAA Member.

${ }^{4}$ Principal Systems Engineer, The MITRE Corporation, McLean, VA 22102.

${ }^{5}$ Mathematician, Federal Aviation Administration William J Hughes Technical Center, Atlantic City, NJ 08405

${ }^{6}$ ADS-B Applications Manager, Federal Aviation Administration, Washington, DC 20597.

${ }^{7}$ Technical Advisor, Air Traffic Systems, Federal Aviation Administration, Washington, DC 20597.

${ }^{8}$ Senior Aerospace Engineer, National Aeronautics and Space Administration, Langley Research Center, Hampton, VA 23681, member
}

American Institute of Aeronautics and Astronautics 
relative to a target aircraft. This increases throughput in capacity-constrained airspace without negatively impacting controller workload and task complexity.

Interval Management can be used for many types of operations: from departure spacing, to miles-in-trail operations, to spacing on arrival and approach. For a capacity-constrained Top 35 airport, IM is one of three NextGen components in the overall arrival flow management system. The first component, Time-based Flow Management (TBFM) (which includes Terminal Sequencing And Spacing [TSAS] ${ }^{9}$, Extended Metering, and Coupled Scheduling), manages the overall plan for aircraft arrivals to the airport facility. This includes runway assignments, an arrival schedule to the runway, and the associated schedule at the upstream points. Given this plan, the second component involves the controller managing the tactical traffic situation to the schedule. Controller experience is augmented with ground automation tools such as Ground-based Interval Management - Spacing (GIM-S) Speed Advisories for en route controllers and TSAS Controller Managed Spacing tools for terminal area controllers to accurately deliver aircraft to frozen Scheduled Times of Arrival (STAs) at the meter fix, upstream meter points, and meter points inside the terminal area.

The third component is IM, which is used to help manage the overall arrival traffic flow. IM Operations for arrival and approach are expected to provide increased runway throughput at peak times of activity, which reduces arrival delay. During the IM Operation, the aircraft manages its speed in order to achieve the relative Assigned Spacing Goal assigned by the controller. The precise management of the inter-aircraft spacing, i.e., less variability, allows for the IM pair to be spaced closer to the operational goal.

In 2010, the Federal Aviation Administration (FAA) chartered the ADS-B In Aviation Rulemaking Committee (ARC) to recommend future uses of ADS-B In. The ARC's 2012 report [1] recommended five applications for further development. Three of those are domestic uses of IM capabilities, and the FAA is currently developing a concept of operations and functional requirements for the first recommended application: IM arrival and approach operations to a single runway. The other two recommended IM domestic applications, IM with Defined Interval and IM for closely spaced parallel runways, are currently being matured for the development of avionics standards by the FAA and RTCA. Concurrently, the National Aeronautics and Space Administration (NASA), through its Air Traffic Management Technology Demonstration-1 (ATD-1) activity, is developing and testing an integrated arrival flow management system with IM to improve arrival efficiencies.

This paper will provide some historic context for the current state of IM including early foundational research, standards development, and flight evaluations. The paper continues with a summary of the current state of IM development, including the development of avionics standards and early steps of the FAA investment decision to develop ground automation requirements to support IM Operations. The path from research, development and standards to a fully operational system is described, including FAA and NASA plans for future IM flight demonstrations. Finally, this paper will discuss the steps being taken to develop Advanced Interval Management, which may enable new classes of operations such as spacing to dependent runways, spacing during departures, spacing in the oceanic environment, and the use if IM to possibly reduce separation standards. Advanced Interval Management will also enable further integration with data communications and other avionics systems.

\section{Background and History}

Aircraft Surveillance Applications (ASAs) have an extensive research and development history and have been examined through human-in-the-loop (HITL) and fast-time simulations as well as several flight tests. These applications range from providing traffic awareness to the pilot to airborne spacing operations to separation and even self-separation operations. Over the years as the operational description, operating environment, and ground automation requirements have evolved, the IM concept has been referred to by a variety of names. IM is used throughout this paper for consistency, though the specific names for predecessor concepts and implementations are used at times to provide historical context.

Although IM Operations can occur in a variety of environments, the majority of IM research to date has been focused on spacing during arrival and approach in en route and terminal airspace using a precise (i.e., not greater than or less than) spacing goal type. Initial work, led mainly by NASA Langley Research Center, focused on flight crews managing in-trail spacing in the terminal environment [2,3]. Soon after, standards started to be developed to enable IM Operations. In the late 1990s and early 2000s, RTCA and the FAA Safe Flight 21 Program started developing the first set of ASA operational concepts and standards. Some of these concepts were basic situation awareness ASAs,

${ }^{9}$ The acronym for Terminal Sequencing And Spacing was changed from TSS to TSAS in mid-2015.

American Institute of Aeronautics and Astronautics 
and others were the first IM concepts. These were eventually termed Approach Spacing for Instrument Approach (ASIA) and Paired Approach (PA). Both applications are conducted in the terminal approach-controlled, surveillance airspace during approach operations under Instrument Flight Rules (IFR). ASIA is conducted to single runways and PA is conducted to closely-spaced parallel runways. ASIA's preliminary requirements were defined in the Minimum Aviation System Performance Standards (MASPS) for Aircraft Surveillance Applications [4]. It was treated as a "probe" application to help determine equipment requirements for more advanced ASAs. At that time, the PA concept was defined in Bone et al. [5].

Early IM flight tests, called Operational Evaluations, occurred in 1999 and 2000. Operational Evaluation 1 was hosted by Airborne Express and took place at its Wilmington, Ohio hub in 1999. Station keeping and in-trail or lead climbs and descent operations were examined [6]. Flight crews were asked to maintain an in-trail spacing distance from another aircraft while remaining level, climbing, or descending. Pilots found the concept and the associated workload to be acceptable. Operational Evaluation 2 was conducted at Louisville International Airport (KSDF) in 2000. The approach spacing application was examined as both initial approach spacing and final approach spacing [7]. After leveling off at the assigned speed and altitude, flight crews were required to achieve and maintain a set distance within specified tolerances on an arrival procedure in the terminal environment prior to joining final approach and starting final approach spacing. Pilot feedback was generally favorable, but also pointed out areas for improvement. Paired Approach was examined in a 1999 simulation and the concept appeared to be feasible [8]. However in 2000, development activities slowed while other applications were matured based on the belief that PA was a longer term / more advanced application ${ }^{10}$.

From the late 1990s through the mid-2000s, EUROCONTROL examined IM during the arrival and approach phase of flight under its Co-Space project in both fast-time and HITL simulations with pilots and controllers [10, 11]. Both time and distance-based spacing goals were tested. Feedback from pilots and controllers on the operation and its benefits was generally positive.

NASA continued its IM work in this timeframe by conducting HITL simulations [12,13] and flight tests [14]. As part of its Trajectory-Oriented Operations With Limited Delegation (TOOWiLD) concept, NASA Ames examined IM in a pilot and controller HITL simulation [15]. Results continued to be generally positive.

After mainly US development of ADS-B In application standards, RTCA and EUROCAE ${ }^{11}$ co-sponsored an international body called the Requirements Focus Group (RFG) in 2003 to write the operational and technical requirements for an initial set of ADS-B In applications, called Package 1. Package 1 consisted of several traffic situation awareness applications along with IM [16]. Though one of the first applications addressed by the RFG, it was decided that IM development should be deferred until the situation awareness applications neared completion.

During this period, UPS and Aviation Communication \& Surveillance Systems (ACSS) started an IM activity. In 2005, UPS and ACSS announced a SafeRoute partnership to develop and deploy a suite of ASAs including an implementation of IM (at the time called Flight Deck-based Merging and Spacing [FDMS]). UPS was interested in using IM to conduct Optimized Profile Descents (OPDs) while minimizing controller interventions and still delivering aircraft efficiently to the airport. In support of that effort and to further develop IM, the FAA started a government and industry group to define the concept and operational and safety requirements. The group met numerous times between 2005 and 2007 to mature the concept from both air and ground perspectives.

During this time, HITL simulations with pilots and controllers were conducted by The MITRE Corporation [17-20] and NASA [21, 22] to further refine the concept. During the same period, flight tests were conducted on a ground capability termed Airline-Based En route Sequencing and Spacing (ABESS), which was intended to set up aircraft for IM [23]. ABESS used radar track information to predict the aircraft sequence at an en route merge point. That information was then used to set an aircraft sequence and set en route speeds. After equipment and operations were approved, UPS conducted the first flight in January of 2008 and continued flights during targets of opportunity until 2010. Two flight tests were conducted during this period with the final one in 2010 [24]. In this test, strings of aircraft started IM in Albuquerque Center (ZAB) en route airspace, performed IM during an OPD, and terminated around the Final Approach Fix at KSDF. Feedback from pilots and controllers remained positive and in general, pilots who

${ }^{10}$ Paired Approach has since been further defined in ref. [9] and is now being developed as an Advanced IM application, described later in this paper.

${ }^{11}$ In the US, avionics standards are developed through RTCA, which is a federal advisory committee that provides a venue for bringing together diverse groups of stakeholders in order to reach consensus and make recommendations to the FAA. EUROCAE provides a similar service to EUROCONTROL and other stakeholders in Europe.

American Institute of Aeronautics and Astronautics 
showed better conformance to the IM Speed commands showed better final spacing performance than pilots who did not. However, difficulties with implementing ABESS and other, non-IM problems curtailed further testing and development.

Concurrent with these activities, an international body called Action Plan 23 (AP23) started meeting in 2006 to identify the next set of ASAs after Package 1. In 2008, the list of ASAs from AP23 and the RFG Package 1 ASAs were used within the FAA to start writing a document called the Application Integrated Work Plan (AIWP) [25, 26]. The AIWP was intended to be a coordination document with the aviation community to gain agreement on high-level operational concepts and priorities for ASAs, including IM. The document summarized ASA concepts and captured their associated maturities, benefits, costs, and technology enablers.

During the latter part of the various field activities around 2008, the RFG reengaged and started defining the Sequencing \& Merging (S\&M) concept, which was a predecessor to IM. Developed for arrival and approach operations, S\&M contained avionics functions providing speed guidance to help a flight-crew achieve a specified spacing interval at a merge point and then maintain that spacing interval once both the IM and target aircraft are on a common route [27]. In the S\&M concept, spacing to the merge point was only possible when both aircraft were direct to the merge point. Later, the constraint that the target and trailing aircraft needed to be direct to the merge point to begin the spacing operation was removed and the concept became known as Merging \& Spacing (M\&S). However, stakeholders participating in the standards activities recognized the potential benefits of more precise inter-aircraft spacing in a number of environments, and the term Interval Management was adopted to represent the broader scope.

Around this same time, the ADS-B In ARC was considering ADS-B applications for recommended future development. The ARC used the FAA AIWP report to conduct its activities and provide recommendations. The original ARC letter and report to the FAA included several variations of IM among its recommended applications [28]. The ARC made a recommendation to the FAA to focus funding on flight-deck and ground technical and operational requirements material for a selected set of ten prioritized applications. Four IM applications were included in those top ten, including one implementation in the top five. The ARC reported that the top five applications provided $77 \%$ of the total benefits. Concurrently, the initial set of IM avionics standards were published by RTCA in 2011 [29].

\section{Current State}

The Interval Management concept has coalesced into three general phases. The first is the implementation of Groundbased Interval Management - Spacing ${ }^{12}$, which is intended to support more frequent use of OPDs and help set-up traffic for successful IM Operations. The GIM-S capability resides only in ground automation and does not require any specific aircraft equipage. The second phase is termed IM-S Arrival, Approach and Cruise (IM-S AA\&C), which enables the use of IM for arrival spacing to a single runway and en route miles-in-trail operations. As deployment nears for the IM-S AA\&C applications, the FAA and RTCA are maturing concepts and communication requirements for a follow-on set of IM capabilities and operations termed Advanced Interval Management (A-IM). The GIM-S and IM AA\&C operations are described next, including considerations for NAS integration. A-IM is described in Section V.

\section{A. Ground-based Interval Management - Spacing}

When traffic density along an OPD arrival path is less than $40 \%$ of maximum traffic density, an FAA internal assessment found that controllers are able to clear individual aircraft for their OPD arrival and to position them prior to their Top-of-Descent (TOD) without interruption and without excessive vectoring. However, between $40 \%$ and $70 \%$ of maximum traffic density, automation support is necessary to help controllers set up the OPDs efficiently and in such a way that there is little likelihood that the OPD will need to be interrupted. Above $70 \%$ of maximum traffic density, an airborne tool was found to be necessary in order to keep aircraft on their OPDs.

In 2007, the FAA received a Final Investment Decision to develop and deploy GIM-S into the NAS. The GIM-S function is designed to address the 40-70\% maximum traffic density case and should enable more efficient and frequent use of OPDs. GIM-S allocates delay further back in en-route airspace through the use of extended metering. This allows the controller to make small speed adjustments and establish the sequence early, but may require metering

\footnotetext{
${ }^{12}$ The inclusion of "-Spacing" in the concept name is a remnant of a time when there was consideration of IM supporting spacing operations, as described in this paper, as well as delegated separation, where the controller delegates separation responsibility to the flight crew. At the recommendation of the ADS-B In ARC, IM delegated separation operations are not currently being implemented.
}

American Institute of Aeronautics and Astronautics 
points to be established in multiple sectors and managed in a coordinated manner across facilities. In addition, the automation provides the en-route controller with speed advisories they can assign to aircraft during level flight to absorb the delay that has been allocated to the meter point.

Extended metering and speed advisories position aircraft efficiently prior to the TOD for their OPD arrival. Above $70 \%$ traffic density, the controller may have difficulty allowing the aircraft to stay unimpeded on their OPD arrival. At this point, GIM-S can be used to set-up an IM Operation around the TOD, and IM can then be used to ensure spacing throughout the descent and to the runway.

GIM-S achieved Initial Operational Capability at Albuquerque Center in September 2014. Since then, the FAA has been working to adapt, or tune, the automation and procedures to optimize the performance and usability of the tool. Two arrivals into Phoenix Sky Harbor airport, the EAGUL6 and PIING1, are in operation with a third merging arrival stream from adjacent Denver Center (ZDV) being adapted at the time of this writing. A GIM-S deployment strategy for other facilities across the NAS is also currently under development.

\section{B. Interval Management - Spacing For Arrival, Approach, and Cruise}

The IM-S AA\&C concept of operations [30] considers two IM applications that will be beneficial enough to support automation and procedure changes. The first is intended to safely reduce the spacing between arriving aircraft in busy terminal airspace. In an IM arrival and approach operation, an IM-capable aircraft approaches the schedule freeze horizon in en route, metered airspace. TBFM then determines if there is a possible target aircraft scheduled immediately before the IM-capable aircraft. If so, the IM-capable aircraft will be scheduled to a slightly smaller spacing. The smaller spacing can be assigned as the IM aircraft can meet the spacing goal more precisely and consistently than is otherwise possible with currently available tools and procedures. Once the IM-capable and target aircraft are within the expected air-to-air ADS-B range, the controller can issue the IM clearance to the flight crew who will enter the information into their Flight Deck-based Interval Management (FIM) avionics. The FIM avionics assist the flight crew in determining if they will be able to comply with the clearance and then, if the operation is determined feasible, begin presenting speeds (termed IM Speeds) to the flight crew to help them achieve the assigned spacing goal by the desired location (e.g. the final approach fix or other facility-designated location). For this operation, the assigned spacing goal is equivalent to the difference in the scheduled times-of-arrival for the IM and target aircraft at the runway. The IM Operation continues as the aircraft enter the terminal area and controllers have IM situation awareness information presented to them to assist in monitoring the progress of the IM Operation and manage IM and non-IM aircraft on the same arrival. At the planned termination point, at or near the final approach fix, the IM clearance ends and the flight crews begin to configure their aircraft for landing. At any time the controller can terminate the IM Operation and resume conventional control. This may be prompted, for example, by the flight crew notifying the controller that they are unable to continue following the IM Speeds.

A second IM application enhances current miles-in-trail operations where metering is not in use. In this operation, a controller who is providing miles-in-trail delivery to a downstream sector can employ IM to meet the miles-in-trail restriction. As the operating environment is more contained, stretching across only a few sectors, and the assigned spacing goal is given by the known miles-in-trail restriction, there are few ground automation modifications needed. In this operation, the IM clearance would be to either capture the miles-in-trail distance if the aircraft are already intrail, or achieve the miles-in-trail distance at the merge point. The IM aircraft would then maintain the spacing until the controller terminates the IM Operation. While precise management of spacing between aircraft is not necessary in this operation, by delegating the speed management to the IM aircraft, the controller has more time to manage the non-IM aircraft. This is expected to reduce controller workload and result in a smoother flow of traffic.

\section{NAS Automation Integration and Air Traffic Management Technology Demonstration-1}

IM-S AA\&C involves the integration of many different pieces of automation along with changes to existing operating procedures. Both center and terminal area controllers will be involved in IM operations that extend across sector and facility boundaries. Pilot and controller procedures will change. Continued work is needed to determine the best way to leverage the IM capabilities to help controllers best manage their traffic. Conditions to initiate the IM Clearance, such as limits on the differential delay and delivery errors, should be within limits to ensure the feasibility of a proposed IM Operation. IM also introduces a mix of control methods applied on the same stream, and so interactions between a relative spacing operation such as IM, and an absolute spacing operation such as TSAS, must be considered. Given these and other operational variations across the NAS, it can be expected that IM Clearances will need to be designed and tailored as appropriate to the desired environment and operation.

American Institute of Aeronautics and Astronautics 
To better understand how requirements for NAS ground-automation system requirements should be developed to leverage the benefits of IM, NASA commenced the ATD-1 subproject in 2011. Its aims are to achieve increased use of Performance-Based Navigation (PBN) arrival procedures, demonstrate an airborne spacing application enabled by ADS-B In, and accelerate the transfer of NASA scheduling and spacing technologies for operational deployment [31]. The ATD-1 concept integrates scheduling capabilities provided by the Traffic Management Advisor for Terminal Metering (TMA TM) with Controller-Managed Spacing (CMS) tools and FIM avionics. The TMA TM extends the FAA's TBFM system by explicitly modeling PBN procedures inside the terminal area and generating de-conflicted schedules at meter fixes, terminal meter points, and runways [32]. The CMS tools present temporal and spatial schedule information to aid Terminal Radar Approach Control controllers in issuing speed instructions to maintain the schedule [33]. The FIM avionics, based on NASA's Airborne Spacing for Terminal Arrival Routes (ASTAR) algorithm [34], provides flight crews of equipped aircraft with speed commands to achieve their scheduled in-trail spacing, potentially providing additional spacing precision and reducing controller workload [22]. ATD-1 is developing operational prototypes of these technologies for field demonstration and has transferred the TMA TM and TSAS technologies to the FAA for inclusion in TBFM.

\section{Implementation Plans for Interval Management - Spacing for Arrival, Approach, and Cruise Operations}

Building on positive research results and aviation community interest, the FAA has started work on developing and deploying the automation capabilities and procedure changes to enable IM-S AA\&C in the NAS. This includes finalizing the avionics requirements, identifying the ground automation requirements, as well as starting the development of the appropriate procedures, phraseology, and training modifications. In parallel, RTCA has been developing the standards for the FIM avionics which manufacturers can use to develop and certify the FIM avionics. In addition, two flight test activities, by the FAA and NASA, are being planned to evaluate IM Operations including the integration of IM with terminal area automation systems. This section discusses the current state of several activities enabling IM deployment.

\section{A. Investment Decision}

The FAA's Acquisition Management System has several phases of concept and requirements maturity that lead up to a Final Investment Decision, whereby the FAA confirms its plan and associated budget to pursue implementation in the NAS. In July 2015, the FAA approved the Investment Analysis Readiness Decision (IARD), which focused on proving that an operational shortfall exists in the NAS with an imminent need to be addressed. Now the focus is on further refining operational requirements and deriving Air Traffic Control (ATC) automation system requirements. This information is being used to prepare a business case proving that the benefits of implementing the ATC automation system(s) are worth the financial investment by the FAA.

The length of time to go through the Acquisition Management System phases through to a Final Investment Decision can vary, though typically many years of dedicated engineering, cost and benefits analyses, and stakeholder advocacy and collaboration are required. IM-S AA\&C is relatively unique and complex, due to its transformational nature of sharing spacing responsibilities between air traffic controllers and flight crews. It must build on a number of in-process investments (including GIM-S and additional enhancements to the TBFM system). Additionally, the investment proposal will include equipage for a portion of an airline fleet to validate the operational benefits once the ATC Automation system(s) have been modified. These factors significantly increase the effort and time needed to ensure the FAA and other stakeholders are in alignment and have a cost-beneficial business case to pursue implementation. As the stakeholders develop a cohesive vision for this NextGen Program, the final timeline to deployment will become clearer.

\section{B. FIM Avionics Standards, Certification Options, and Prototype Development}

The first standards addressing the FIM avionics needed to support IM AA\&C operations, the Safety, Performance, and Interoperability Requirements Document for Airborne Spacing - Flight-Deck Interval Management (ASPA-FIM), were developed jointly with RTCA and EUROCAE and published in June 2011 [29]. This document defines a set of operational scenarios supported by the avionics, the avionics functions needed to perform in those operations, and safety and performance analyses to verify that the avionics functions satisfy safety requirements and operational objectives, respectively. In 2012, the RTCA and EUROCAE committees started developing the FIM Minimum Operational Performance Specification (MOPS), which were published in October 2015[35]. The ASPA-FIM MOPS provides detailed functional and performance requirements, requirements on the information elements to be displayed to the flight crew during IM Operations, and test procedures that avionics manufacturers must pass as part of the 
avionics certification process. This version ${ }^{13}$ of the FIM MOPS supports federated IM systems, where the IM systems do not require integration with other flight-deck systems (e.g., navigation).

When the ASPA-FIM MOPS development began, the NASA ATD-1 subproject was also looking for opportunities to demonstrate IM as an early ADS-B In application as a part of the ATD-1 integrated arrival solution. Early in the ATD-1 planning process, it was recognized by NASA and the FAA that the ATD-1 demonstration could be used to support the development of standards for FIM equipment that would eventually be certified and approved for use.

Since 2011, NASA and the FAA have collaborated to develop a plan to conduct demonstrations of ADS-B In applications, responding directly to language in the FAA Modernization and Reform Act of 2012 [36] and the final report of the ADS-B In ARC [28]. In addition, the prototype system and associated demonstration would be used to provide results back to the FAA and RTCA to validate some MOPS requirements. That input would be considered by RTCA and the FAA for inclusion in future versions of the ASPA-FIM standards.

In the joint agency plan, resources and expertise were leveraged towards a truly collaborative multi-agency investment that would support the community and achieve more together than could be achieved by either agency alone. The joint agency plan began by recognizing opportunities to leverage each agency's strengths. As such, NASA has partnered with industry leaders in avionics, systems integration, and airlines including The Boeing Company, Honeywell, and United Airlines to build, test and fly a prototype FIM system based on the ASPA-FIM MOPS. This prototype system will include a FIM application integrated into modern avionics systems in a retrofit configuration with federated systems. This will help control costs and manage the staging of flight assets for the flight test and demonstration.

The FAA is actively participating in this activity with NASA by participating in the design review panels and the working groups. These working groups are evaluating the system requirements for consistency with the FIM MOPS, as well as refining the Human Machine Interface (HMI) and the plans for the flight test. Once NASA has completed testing and demonstration of the prototype FIM system, all of the deliverables from this effort including the hardware, software, documentation, operator manuals, training materials, and results will be transferred to the FAA for further testing and government use.

\section{Flight Trials}

Following on the UPS activities, ACSS partnered with American Airlines (US Airways at the time) in 2008 to install the SafeRoute equipment in 20 Airbus A330 aircraft. As with UPS, that equipment included an implementation of IM called Merging and Spacing (M\&S). Limited M\&S operational testing began in the spring of 2015 for aircraft crossing the Atlantic and operating in en route airspace. Data will be collected to examine spacing performance and operator acceptability and will be available to the FAA to inform further requirements and procedures development.

In December 2014, NASA, the FAA and The Boeing Company conducted a proof of concept flight test to assess the risks of conducting ADS-B In application flight tests that require coordinated aircraft and control of test conditions expected in the NASA ATD-1 Flight Test. The ASTAR algorithm was installed on board the Boeing EcoDemonstrator 787 in a very low cost test configuration and used to conduct IM arrival operations into Grant County International Airport in Moses Lake, WA. NASA and Boeing observers were also present in the relevant FAA facilities during the flight test to observe in situ operations and support the FAA facilities as needed. Results of this test are reported in ref. [37].

The FAA and the NASA ATD-1 sub-project are planning to use a prototype of FIM avionics to conduct flight testing starting in 2017. This flight testing is designed to test a range of capabilities within the FIM system prototype based on the ASPA-FIM MOPS and examine the integration of flight-deck and ground-automation requirements. Objectives will be to ensure that ASPA-FIM MOPS compliant aircraft will function successfully with the supporting IM-S AA\&C ground automation as well as to demonstrate algorithm speed guidance stability and spacing performance across a variety of design implementations.

For the NASA ATD-1 flight test and demonstration, three aircraft will participate in a string for arrival and cruise IM operations using the same airspace utilized in the ASTAR Flight Test in December 2014. The first (lead) aircraft will be a business jet operated by Honeywell that will act as the target aircraft broadcasting ADS-B Out. This aircraft will fly cruise and descent profiles representative of air transport category aircraft on arrival into a busy terminal area. This is done through the use of prescribed speeds and tightly-managed initial conditions. The other two aircraft will be a

\footnotetext{
${ }^{13}$ A second version of the FIM MOPS will be developed to support Advanced IM concepts, described in Section V, and the standard will also support the integration of IM with other flight-deck systems.
}

American Institute of Aeronautics and Astronautics 
Boeing 757-200 operated by Honeywell and a Boeing 737-900 operated by United Airlines. Both the B757-200 and B737-900 will be equipped with DO-260B-compliant ADS-B In/Out and the prototype FIM avionics system.

Test conditions will include a range of independent variables. These variables are based on the results of numerous fast-time and real-time studies conducted within ATD-1. The independent variables include the IM clearance type, the delay imposed on the ADS-B Out target aircraft, the route geometry, the pairing geometry, the initial spacing error, and the operational configuration. The IM Clearance types will include the Achieve and Maintain, Capture and Maintain, Maintain Current, and Final Approach Spacing Clearance Types. The speed profiles for the target aircraft will be varied to represent the range of nominal to delayed operations indicative of high-density terminal arrival operations. Route geometries will be tested that include downwind and shortside arrivals. Special procedures will be developed for the flight test to represent modern terminal airspace procedures such as Area Navigation (RNAV) arrivals and Required Navigation Performance (RNP) transitions to Instrument Approach Procedures. Pairing geometries, in-trail and merging, will be tested for each pair of aircraft in the string. Initial spacing errors will also be varied to test the range of pair-wise relative spacing that the FIM avionics is expected to encounter operationally upon initiation. Additionally, each clearance type will be tested with a set of operational configurations. For example, the Achieve and Maintain clearance type will vary the location of the Achieve-By-Point to include the meter fix, a merge point inside terminal airspace, or the final approach fix.

IM system performance will be assessed based on data collected on board the three aircraft. Human factors data will be collected from test pilots through research observers and surveys. Pilot training will be conducted by the aircraft operators to ensure safe operations are conducted and flight test procedures are well understood. NASA Langley Research Center will provide IM system training for the pilots to establish a baseline proficiency with the IM system prior to the flight test. As was the case in the 2014 ATD-1 Flight Test, NASA observers will also be posted in the relevant Air Traffic Control facilities to monitor the flight test from the ground and support the FAA facilities as needed.

Building on the NASA ATD-1 flight test, the FAA plans to conduct a flight test of the integrated IM system, which includes prototype ground automation systems based on the final Program Requirements for the IM-S AA\&C investment. Besides being the first flight demonstration of a fully integrated IM-S AA\&C system, the objective of this flight test will be to test whether differences between air and ground trajectory generation lead to interoperability issues. The flight test is timed so that the revision to RTCA FIM avionics standards can reflect what is learned, ensuring that fielded avionics will perform successfully in the NAS.

The ground automation under test is planned to be built from a baseline integrated system of all three platforms (TBFM, ERAM, and STARS), which includes GIM-S and a prototype version of TSAS. The focus of the prototypes will be on trajectory generation, scheduling, and IM Clearance generation requirements. The avionics will be based on the FIM prototype used in the NASA flight test, modified based on lessons learned from that activity. The ground automation will be developed at the FAA's William J. Huges Technical Center in Atlantic City, NJ.

Test pilots and controllers will participate in the initiation and execution of the full range of IM-S AA\&C clearances and scenarios included in the IM-S AA\&C concept. These operations will be conducted in airspace around Atlantic City (KACY) TRACON using special procedures developed for the flight test, likely leveraging those procedures used in the NASA flight test. Procedures will represent modern arrival and approach procedures such as RNAV arrivals and RNP transitions to Instrument Approach Procedures.

\section{Advanced Interval Management}

There are several capabilities desired for IM operations which are not yet mature enough to be part of the IM-S AA\&C concept and automation development. These include additional environments, such as departure operations or multiple dependent runway operations, as well as integration of the FIM avionics with advanced navigation and communication technologies. Together these new capabilities are called A-IM. Development of the avionics requirements for A-IM began in October 2015 and will build on the RTCA DO-328A and DO-361 standards [35, 38]. Work on ground automation requirements by the FAA will start soon after the IM AA\&C requirements are finalized. A-IM applications are expected to become available in the 2020 - 2025 timeframe.

A-IM will leverage Data Communications (Data Comm) capabilities when possible to provide IM Clearance and other information. For example, Data Comm will allow for more complex IM Clearances including non-published routing and constraints for the Target Aircraft. In IM-S AA\&C, the Target Aircraft must either be on the same navigation route as the IM Aircraft or be following a published navigation procedure that can be communicated via voice so that

American Institute of Aeronautics and Astronautics 
the pilot of the IM Aircraft can enter the procedure name into the FIM avionics for processing. Data Comm will allow for a wider range of navigation procedures for the Target Aircraft including Dynamic Required Navigation Performance (DRNP) routes. A joint RTCA/EUROCAE committee is currently developing the Data Comm message standards that will support A-IM operations. Those standards are scheduled to be published in early 2016.

The IM system will also need to be designed to work cooperatively with the aircraft's navigation system to improve trajectory predictions and performance. An example of this implementation would be one in which the FIM avionics receive the Flight Management System (FMS)-calculated estimated time of arrival (ETA) to the point at which the spacing is desired for the ownship as opposed to computing an independent ETA. The FIM avionics could also provide speed guidance directly to the FMS or auto-throttle system, to reduce flight crew workload and allow for finer control of the speed.

The new applications being defined under A-IM are summarized in Table 1 and briefly described in the following sections. Further concept detail is available in the A-IM Operational Service Descriptions [39, 40].

Table 1: Advanced Interval Management Applications

\begin{tabular}{l|ll}
\hline Domain & A-IM Application & \\
\hline & A-IM A\&A & Single Runway Operations w/ A-IM Enhancements \\
& A-IM DCCR & Dependent Converging and Crossing Runway Operations \\
$\begin{array}{l}\text { Arrival and } \\
\text { Approach }\end{array}$ & A-IM DSA1 & Dependent Staggered Arrivals with One Target \\
& A-IM DSA2 & Dependent Staggered Arrivals with Two Targets \\
& A-IM PA & Paired Approach \\
Departure & A-IM DO & Departure Operations \\
Oceanic & A-IM PTM Oceanic & Pairwise Trajectory Management - Oceanic \\
\hline All & A-IM DI & Defined Interval \\
\hline
\end{tabular}

\section{A. A-IM in the Arrival and Approach Domain}

In the Arrival and Approach domain, multiple controllers work the arrival flows to a busy airport assisted by future TBFM enhancements to help establish the desired airport landing sequence. With single runway IM-S AA\&C operations, IM Aircraft space relative to aircraft directly ahead and are not constrained by aircraft on a parallel runway. The initial performance of these operations is expected to improve with A-IM through the provision of more detailed target aircraft trajectory and wind information. A-IM also accommodates pairwise spacing between aircraft landing on different runways. In the case of crossing or converging runways, the A-IM Dependent Crossing and Converging Runways (DCCR) application is used to keep an IM Aircraft a desired distance from its runway threshold when the Target Aircraft crosses its threshold. This will raise the airport acceptance rate by allowing operations to crossing runways that would not otherwise be possible. In the case of dependent parallel runways, the IM Aircraft achieves a spacing goal relative to either a single Target Aircraft arriving on the parallel runway only (DSA1), or to an aircraft arriving on the parallel and a target aircraft arriving at the same runway (DSA2). Figure 1 shows a possible set-up for DSA2 operations. The IM Aircraft, TRL03, is managing its spacing relative to both LED01 and LED02. If LED02 was not present, this operation reduces to the standard A-IM AA\&C single runway operation. If LED01 was not present, this would become a DSA1 operation.

American Institute of Aeronautics and Astronautics 


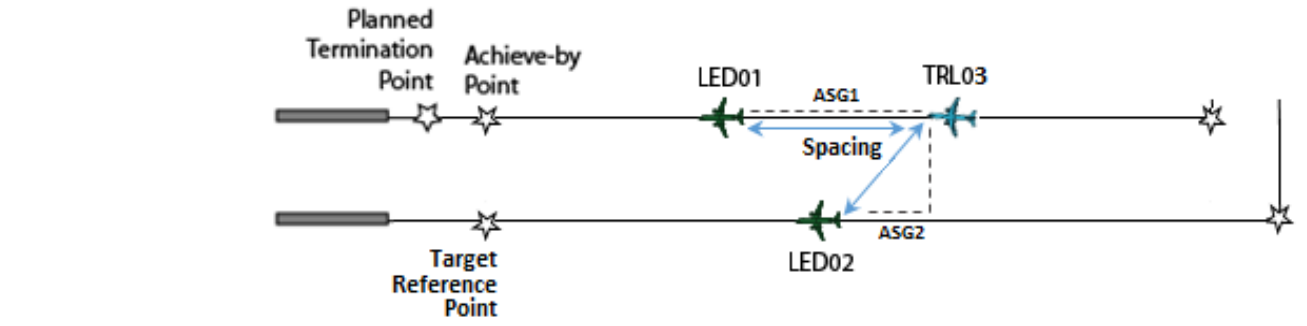

Figure 1: Schematic of DSA2 Operations where the IM Aircraft (TRLO3) is managing spacing relative to both LED01 and LED02.

A-IM ensures that current requirements for both single runway approach spacing (for the target aircraft landing on the same runway as the IM aircraft) and diagonal separation (for the target aircraft landing on the parallel runway) are met. As in the single runway case, it is expected that the precise spacing provided by IM will allow for spacing closer to the required in-trail and diagonal separation.

For the DSA2 operation, the FIM avionics will provide guidance such that the spacing interval at the point at which the spacing is desired will equal or exceed the Assigned Spacing Goals for each aircraft. It requires arbitration logic within the speed guidance algorithm to determine which Target Aircraft is actively driving the IM Speed and which target is being monitored. Depending on traffic geometry and spacing goal, the speed guidance may change targets during the operation. In a HITL simulation of a DSA2 operation, flight crews found the IM concept, procedures, and interfaces acceptable, and associated workload levels were low [41].

A-IM Paired Approach operations can provide airports an all-weather capability to enable continued minimized interarrival time of successive landings at closely spaced parallel runways when environmental conditions preclude the use of visual separation. For dependent parallel runways closer than $2500 \mathrm{ft}$, PA allows aircraft to space closer than the separation currently allowed. For these operations, ATC identifies suitable pairs of aircraft and delivers them to the final approach course with an interval suitable to the operation. The trailing aircraft receives an IM Clearance to conduct the Paired Approach, which provides guidance to an Assigned Spacing Goal to protect against collision in the event of a blunder and hazardous wake encounter. The FIM avionics then provide IM Speeds that drive toward the Assigned Spacing Goal, which is designed to keep the IM aircraft in a safe in-trail position behind the target aircraft. Should it become impossible to safely continue operations, a breakout or escape maneuver must be flown. In recent flight deck and ATC Paired Approach HITL simulations, pilots and controllers found the concept to be generally feasible and operationally acceptable [9].

\section{B. A-IM in the Departure Domain}

A-IM also enables an aircraft to manage its spacing relative to another aircraft in the departure domain. General IM DO involves aircraft departing from one or more airports out to a departure fix or gate. Controllers can use IM to deliver both in-trail and merging aircraft to the fix or gate at a precise rate. These operations proceed similarly to IM Arrival and Approach in that the controller clears an IM-capable aircraft to achieve a desired spacing at a desired location relative to a target aircraft's trajectory. The FIM avionics then provides IM Speeds during the climb in order to help the flight crew meet the clearance. In an initial flight deck simulation of IM DO, flight crews reported that the operation was generally feasible and acceptable [42].

\section{A-IM in the Oceanic Domain and Defined Interval}

A-IM also includes a concept for Pairwise Trajectory Management (PTM) that has been developed to allow aircraft to resolve a specific traffic conflict (or conflicts) identified by the ground system with a potentially more efficient maneuver, spacing, or altitude assignment and a possible reduction in controller workload [40]. Initially being defined for the Oceanic domain, PTM is expected to eventually be extended to operations in domestic airspace.

In addition, the IM Defined Interval (DI) concept is being developed to leverage IM flight deck and ground capabilities to increase capacity and throughput when operating close to separation minima. DI is considered an extension across IM Operations and will enable aircraft to maintain closer spacing than would otherwise be possible under today's separation minima, without delegating separation responsibility from ATC to the flight deck. In some cases, DI may also allow for a reduction in current separation minima. Details for how the DI capability may change the associated roles and responsibilities of controllers, traffic managers, pilots; spacing and separation procedures; and equipment and system requirements are still being defined.

American Institute of Aeronautics and Astronautics 


\section{Conclusion}

IM operations use emerging technologies, such as ADS-B In, and a reallocation of current air traffic tasks to improve the flow of arrival traffic to increase runway utilization. Focused research and development has been on-going for nearly two decades. Numerous studies from organizations in the US and Europe have matured the operations intended for initial deployment, and flight tests are showing the feasibility of and potential improvements from IM Operations. The FAA and NASA are addressing key issues to enable deployment within the next several years, including what is needed for local adaptations, integration with ground metering systems, and the transformational nature of sharing spacing responsibilities between air traffic controllers and the flight crews. The FAA successfully completed IARD and is now preparing for a Final Investment Decision. RTCA and EUROCAE have published the first FIM MOPS, and NASA is demonstrating how IM can be integrated with other terminal area automation that will be in place by the time IM is deployed. Work has also begun on defining the second-generation, or advanced, IM Operations that will allow the FAA to fully realize the benefits and operations recommended by the ADS-B In ARC.

\section{References}

1. $\quad$ ADS-B In ARC. "Recommendations in Response to the Federal Aviation Administration May 30, 2012 , Tasking," 2012.

2. $\quad$ Abbott, T. S., and Moen, G. C. "Effect of Display Size on Utilization of Traffic Situation Display for Self-Spacing Task," NASA TP-1885, 1981.

3. Williams, D. H., and Wells, D. C. "Jet transport flight operations using cockpit display of traffic information during instrument meteorological conditions: Simulation evaluation," NASA TP-2567, 1986.

4. $\quad$ RTCA. "Minimum Aviation System Performance Standards (MASPS) for Aircraft Surveillance Applications (ASA)," DO-289, Washington, DC, 2003.

5. Bone, R., Hammer, J., Mundra, A., Olmos, B., Pollack, M., and Stassen, H. "Paired Approach Operational Concept Version 7," MITRE Paper 00W0000210, 2000.

6. $\quad$ FAA. "Operational Evaluation-1 Final Report," Washington, DC, 2000.

7. $\quad$ FAA. "Operational Evaluation-2 Final Report " Washington, DC, 2001.

8. $\quad$ Bone, R., Olmos, O., and Mundra, A. "Paired Approach: A Closely Spaced Parallel Runway Approach Concept," Washington, DC, 2000.

9. Domino, D. A. T., D., Mundra, A., and Stassen, H. "Paired Approaches to Closely Spaced Runways: Results of Pilot and ATC Simulation," Digital Avionics Systems Conference, Colorado Springs, CO, USA, 2014.

10. Hebraud, C., Hoffman, E., Pene, N., Rognin, L., Sheehan, C., and Zeghal, K. "CoSpace 2003 flight deck experiment assessing the impact of spacing instructions from cruise to final approach," 2004.

11. Grimaud, I., Hoffman, E., Rognin, L., Zeghal, K., and Deransy, R. "EACAC 2000 real-time experiments: initial evaluation of limited delegation of separation tasks to the flight deck," 2001.

12. Oseguera-Lohr, R. M., Lohr, G. W., Abbott, T. S., and Eischeid, T. M. "Evaluation of operational procedures for using a time-based airborne interarrival spacing tool," Digital Avionics Systems Conference, 2002.

13. Barmore, B., Abbott, T., and Capron, W. "Evaluation of Airborne Precision Spacing in a Human-in-the-Loop Experiment," AIAA 5th ATIO and16th Lighter-Than-Air Sys Tech and Balloon Systems Conferences. American Institute of Aeronautics and Astronautics, 2005.

14. Lohr, G. W., Oseguera-Lohr, R. M., Abbott, T. S., Capron, W. R., and Howell, C. T. "Airborne evaluation and demonstration of a time-based airborne inter-arrival spacing tool," NASA/TM-2005-213772, 2005.

15. Mercer, J., Callantine, T. J., Lee, P. U., Prevôt, T., and Palmer, E. "An Evaluation Of Airborne Spacing In The Terminal Area," The 24th Digital Avionics Systems Conference, 20052005.

16. Stienleitner, J. "Package I Requirements Focus Group "Rapid Global Harmonisation," 3rd ASAS Thematic Network Workshop, Toulouse, France, 2004.

17. Penhallegon, W. J., and Bone, R. S. "Evaluation of a flight deck-based merging and spacing concept on en-route air traffic control operations," 7th USA/Europe Air Traffic Management R\&D Seminar, Barcelona, Spain, 2007.

18. Bone, R. S., and Penhallegon, W. J. "En-route flight deck-based merging and spacing impact on flight crew operations," Digital Avionics Systems Conference, 2007 DASC'07 IEEE/AIAA 26th, 2007.

19. Penhallegon, W. J., and Bone, R. S. "Flight deck-based merging and spacing impact on flight crew operations during continuous descent arrivals and approaches," Digital Avionics Systems Conference, 2008 DASC 2008 IEEE/AIAA 27th, 2008.

20. Penhallegon, W. J., and Bone, R. S. "Flight Deck-Based Merging and Spacing during En Route Descent: Findings from an Air Traffic Controller Simulation," 8th USA / Europe Air Traffic Management R\&D Seminar, Napa, CA, 2009.

21. Prevot, T., Callantine, T., Homola, J., Lee, P., Mercer, J., Palmer, E., and Smith, N. "Air/ground simulation of trajectoryoriented operations with limited delegation," Proceedings of the 7th USA/Europe Air Traffic Management Research and Development Seminar, Barcelona, Spain, 2007.

22. Murdoch, J. L., Barmore, B. E., Baxley, B. T., Capron, W. R., and Abbott, T. S. "Evaluation of an airborne spacing concept to support continuous descent arrival operations," Eighth USA/Europe Air Traffic Management Research and Development Seminar (ATM2009), Napa, CA, 2009.

American Institute of Aeronautics and Astronautics 
23. FAA. "Airline Based En Route Sequencing and Spacing Concept of Operations Description, Version 1.6," Washington, DC, 2007.

24. Penhallegon, W., Bone, R., and Stassen, H. P. "Field test of interval management. Spacing during an optimized profile descent arrival and approach.." The MITRE Corporation, McLean, VA, 2015.

25. $\quad$ FAA. "Application Integrated Work Plan (version 1)," Washington, DC, 2009.

26. $\quad$ FAA. "Application Integrated Work Plan (version 2)," Washington, DC, 2010.

27. Hoffman, E., Ivanescu, D., Shaw, C., and Zeghal, K. "Analysis of Spacing Guidance for Sequencing Aircraft on Merging Trajectories," Digital Avionic Systems Conference, Irvine, CA, 2002.

28. ADS-B In ARC. "Recommendations to Define a Strategy for Incorporating ADS-B In Technologies into the National Airspace System," 2011.

29. RTCA. "Safety, Performance and Interoperability Requirements Document for Airborne Spacing - Flight Deck Interval Management (ASPA-FIM)," DO-328, Washington, DC, 2011.

30. FAA. "Interval Management (IM-S) for Arrival-and-Approach and Cruise Concept of Operations (ConOps)," SBS-089, Revision 01, Washington, DC, 2014.

31. Prevot, T., Baxley, B., Callantine, T., Johnson, W., Quon, L., Robinson, J., and Swenson, H. N. "NASA's ATM Technology Demonstration-1: Transitioning fuel efficient, high throughput arrival operations from simulation to reality," Proceedings of the International Conference on Human-Computer Interaction in Aerospace (HCI-Aero 2012), Brussels, 2012.

32. Swenson, H. N., Thipphavong, J., Sadovsky, A., Chen, L., Sullivan, C., and Martin, L. "Design and evaluation of the terminal area precision scheduling and spacing system," Proceedings of Ninth USA/Europe Air Traffic Management Research and Development Seminar, Berlin, 2011.

33. Kupfer, M., Callantine, T., Martin, L., Mercer, J., and Palmer, E. "Controller support tools for schedule-based terminalarea operations," Proceedings of the Ninth USA/Europe Air Traffic Management Research and Development Seminar, Berlin, 2011.

34. Abbott, T. S. "An Overview of a Trajectory-Based Solution for En Route and Terminal Area Self-Spacing: Fourth Revision," NASA/CR-2013-218044, 2013.

35. RTCA. "Minimum Operational Performance Standards (MOPS) for Flight-deck Interval Management (FIM)," DO-361, Washington, DC, 2015.

36. $\quad$ FAA Modernization and Reform Act of 2012. Pub.L. 112-95, 2012

37. Roper, R. D., and Koch, M. R. "Proof-of-Concept Flight Test for Interval Management," AIAA Guidance, Navigation, and Control Conference, San Diego, CA, 2016.

38. RTCA. "Safety, Performance and Interoperability Requirements Document for Airborne Spacing - Flight Deck Interval Management (ASPA FIM)," DO-328A Washington, DC, 2015.

39. RTCA. "Advanced Interval Management Arrival \& Approach, Departure, and Defined Interval Operational Service Description v1," Washington, DC, 2015.

40. $\quad$ RTCA. "Advanced Interval Management Pairwise Trajectory Management (PTM) Operational Service Description v1," Washington, DC, 2015.

41. Baxley, B. T., Murdoch, J. L., Swieringa, K. A., Barmore, B. E., Capron, W. R., Hubbs, C. E., Shay, R. F., and Abbott, T. S. "Experiment Description and Results for Arrival Operations Using Interval Management with Spacing to Parallel Dependent Runways (IMSPiDR)," NASA/TP-2013-217998, 2013.

42. Penhallegon, W. J., Mendolia, A. S., Bone, R. S., Orrell, G. S., and Stassen, H. P. "Flight Deck-Based Interval Management-Spacing During Departures: Flight Crew Human-In-The-Loop Simulation," 9th USA/Europe Air Traffic Management Research and Development Seminar, Berlin, Germany, 2011.

American Institute of Aeronautics and Astronautics 